\title{
EXCITATION WITH A SERIES OF PULSES OF A LINEAR PULSE ELECTRODYNAMIC TYPE CONVERTER OPERATING IN POWER AND HIGH-SPEED MODES
}

Purpose. The aim of the article is to increase the efficiency of linear pulse electrodynamic type converter (LPEC) when operating in high-speed and force modes by reducing the amplitude of the recoil force by exciting its windings with a series of pulses from the capacitive energy storage (CES). Methodology. Using the LPEC mathematical model, in which the equations describing the interconnected electrical, magnetic, mechanical and thermal processes are presented in a recursive form, the electrodynamic and electromechanical characteristics of LPEC are simulated by excitation by a single and a series of pulses from CES sections. Results. It was found that when a single pulse is excited by an LPEC operating in a high-speed mode, in which the armature accelerates the actuator, compared with the force mode in which the armature is inhibited, the current amplitude in the windings decreases by $7.5 \%$, and the amplitudes of electrodynamic force (EDF) - by $21.8 \%$, impulse values of EDF - by $27.1 \%$. In this case, the armature winding with the actuating element accelerates to a speed of $7.1 \mathrm{~m} / \mathrm{s}$. When excited by a series of pulses from the same sections of the CES during LPEC operation in the force mode, the amplitudes of the current pulses and the EDF are practically unchanged, and when operating in high-speed mode, the amplitudes of the currents and the EDF gradually decrease. Both in power and in high-speed operating modes, an increase in the number of excitation pulses while conserving the energy of the CES leads to a decrease in the main indicators of LPEC. But by reducing the amplitude of the EDF, which manifests itself as a recoil force, the efficiency of $L P E C$ increases. Originality. It is shown that the excitation of $L P E C$ by a series of pulses increases the efficiency of LPEC when operating in high-speed and power modes, providing a minimum amplitude of the EDF, which determines the recoil force acting on the inductor winding. Practical value. For LPEC operating in high-speed mode, it is proposed to reduce the maximum current amplitudes and EDF due to the sequential increase in capacitances of sections of the CES, forming a series of excitation pulses. For LPEC, operating in force mode, it is advisable to use the same capacities of all sections of the CES. References 22, figures 9.

Key words: linear pulse electrodynamic type converter, mathematical model, high-speed and force operation mode, excitation by a series of pulses, recoil force, efficiency criterion.

Представлена математична модель лінійного імпульсного перетворювача електродинамічного типу (ЛІПЕТ), в якій рішення рівнянь, що описують взаємопов'язані електричні, магнітні, механічні та теплові процеси, подані в рекурентному вигляді. Досліджено електромеханічні і електродинамічні характеристики ЛІПЕТ при роботі в швидкісному режимі, що забезпечує прискорення обмотки якоря з виконавчим елементом, та в силовому режимі при загальмованій обмотці якоря. Показано, що при збудженні одиночним імпульсом ЛІПЕТ, який працює в швидкісному режимі, в порівнянні $з$ силовим режимом, відбувається зменшення амплітуди струму в обмотках на 7,5 \%, амплітуди електродинамічних зусиль (ЕД3) - на 21,8 \%, значення імпульсу ЕД3 - на 27,1\%. При цьому обмотка якоря 3 виконавчим елементом розганяється до швидкості 7,1 м/с. При збудженні серією імпульсів від однакових секцій ємнісного накопичувача енергї̈ (СНЕ) та роботі ЛІПЕТ в силовому режимі амплімуди імпульсів струму $і$ ЕДЗ практично незмінні, а при роботі в швидкісному режимі відбувається послідовне зменшення цих амплітуд. Збільщення кількості імпульсів збудження при збережсенні енергії СНЕ призводить до зменшення основних показників ЛІПЕТ. Але за рахунок зменшення амплітуди ЕДЗ, яка проявлясться як сила віддачі, ефективність ЛІПЕТ збільшується. Для ЛІПЕТ, що працює в швидкісному режимі, запропоновано зменшення максимальних амплітуд струму і ЕДЗ за рахунок послідовного збільшення ємностей секцій СНЕ, які формують серіӥ імпульсів збудження. Для ЛІПЕТ, цио працює в силовому режимі доцільно використовувати однакові ємності всіх секцій СНЕ. Бібл. 22 , рис. 9. Ключові слова: лінійний імпульсний перетворювач електродинамічного типу, математична модель, швидкісний і силовий режим роботи, збудження серією імпульсів, сила віддачі, критерій ефективності.

Представлена математическая модель линейного импульсного преобразователя электродинамического типа (ЛИПЭТ), в которой решения уравнений, описывающцх взаимосвязанные электрические, магнитные, механические и тепловые процессы, представлены в рекуррентном виде. Исследованы электромеханические и электродинамические характеристики ЛИПЭТ при работе в скоростном режиме, обеспечивающем ускорение обмотки якоря с исполнительным элементом, и в силовом режиме, когда обмотка якоря заторможена. Показано, что при возбуждении одиночным импульсом ЛИПЭТ, работающего в скоростном режиме, по сравнению с силовым режимом происходит уменьшение амплитуды тока в обмотках на 7,5 \%, амплитуды электродинамических усилий (ЭДУ) - на $21,8 \%$, значения импульса ЭДУ - на 27,1\%. При этом обмотка якоря с исполнительным элементом разгоняется до скорости 7,1 м/с. При возбуждении серией импульсов от одинаковых секций емкостного накопителя энергии (ЕНЭ) и работе ЛИПЭТ в силовом режиме амплитуды импульсов тока и ЭДУ практически неизменны, а при работе в скоростном режиме происходит последовательное уменьщение амплитуд токов и ЭДУ. Увеличение количества импульсов возбуждения при сохранении энергии ЕНЭ приводит к уменьшению основных показателей ЛИПЭТ. Но за счет уменьшения амплитуды ЭДУ, которая проявляется как сила отдачи, эффективность ЛИПЭТ увеличивается. Для ЛИПЭТ, работающего в скоростном режиме, предложено уменьщение максимальных амплитуд тока и ЭДУ за счет последовательного увеличения емкостей секций ЕНЭ, формирующих серии импульсов возбуждения. Для ЛИПЭТ, работающего в силовом режиме, целесообразно использовать одинаковые емкости всех секций ЕНЭ. Библ. 22 , рис. 9. Ключевые слова: линейный импульсный преобразователь электродинамического типа, математическая модель, скоростной и силовой режим работы, возбуждение серией импульсов, сила отдачи, критерий эффективности. 
Introduction. Linear pulse electrodynamic type converters (LPEC) are widely used to accelerate the actuator (A) to high speed in a short active section and to create powerful force pulses on the target with a slight movement of the A [1-3]. Such converters operating in both high-speed and force modes are widely used in many branches of science and technology as electromechanical accelerators of A and shock-force devices [4, 5].

As the analysis shows, LPECs have improved force and speed indicators compared to inductive and electromagnetic converters which are also widely used for similar applications [6].

In the induction-type converter, the armature is made in the form of a single or multi-turn short-circuited winding, in which current is induced from the inductor winding. However, due to the phase shift between the currents in the windings of the inductor and the armature, in addition to the electrodynamic forces of repulsion, parasitic attractive forces also arise. As a result, the efficiency of such a converter decreases [7].

An electromagnetic type converter has an armature made ferromagnetic and an electromagnetic force of attraction acts on it from the side of the inductor winding. However, due to the physical properties of a ferromagnetic, in such a converter electromagnetic processes are slow in nature with relatively low force amplitudes. This also leads to low efficiency of the electromagnetic type converter, especially when operating in high-speed mode [8].

LPEC contains a movable armature winding (AW), which electrodynamically interacts with the stationary indictor winding (IW) $[9,10]$. These windings are usually connected in series and are excited from a capacitive energy storage device (CES). Since both windings are wound counterclockwise in magnetic field, electrodynamic repulsive forces (EDF) arise between them. LPEC windings are multi-turn in the form of disks coaxially mounted opposite each other (Fig. 1).

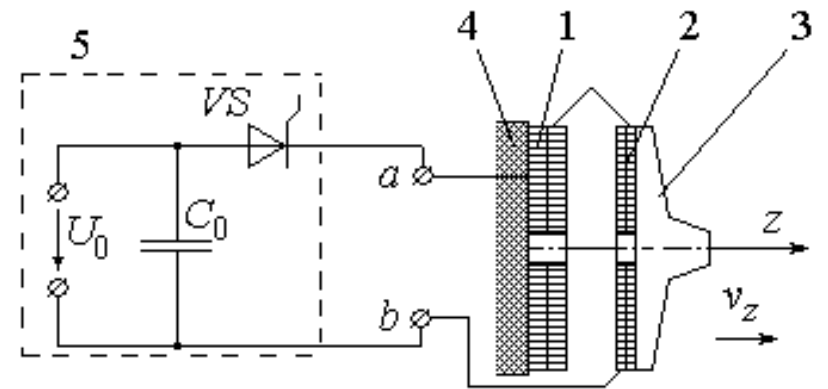

Fig. 1. LPEC diagram:

1 - IW, 2 - AW, 3 - A, 4 - stop, 5 - CES

In the high-speed mode of operation, under the influence of the repulsion EDFs, the AW along with the A axially moves relative to the IW along the $z$ axis with speed $v_{z}$. However, these same EDFs also affect IW, which leads to the appearance of the recoil force of the LPEC. The recoil force negatively affects the functioning of the converter in many technical objects and systems, reducing their mechanical reliability. For a number of applications, for example, riveting, grooving, marking and other manual percussion instruments, for launch systems, for example, catapults for unmanned aerial vehicles, various autonomous starters, and others, the recoil force negatively affects both the device itself and the operating personnel [11]. The recoil force is especially negative in various measuring devices. For example, in a ballistic laser gravimeter designed to measure the acceleration of gravity, an electromechanical catapult is used, which provides a vertical toss of the A - an angular optical reflector [12]. This reflector is an integral part of the measurement system of a Michelson laser interferometer. The recoil force arising during the tossing of the A causes autoseismic oscillations, which reduce the accuracy of measuring gravitational acceleration [13].

Recently, studies of linear pulsed electromechanical converters have appeared, for the excitation of which from the CES various shapes of current pulses generated by electronic devices are used [14]. Of interest is the excitation of a linear electromechanical induction-type accelerator with superconducting magnets by a series of rectangular pulses $[15,16]$. This excitation system is used to recover part of the energy in the power source.

A method of excitation of a linear electromechanical accelerator of induction type by a series of consecutive pulses from sections of the CES is known [17]. However, in this accelerator, each section of the CES is connected to its section of IW, which are offset from each other along the axis of movement of the electrically conductive armature. However, if the IW is made non-partitioned, then such a system does not solve the problem of reducing the recoil force.

Thus, a decrease in the amplitude of the EDFs, manifested in the form of a recoil force, when the LPEC performs its functions in high-speed and force modes, is an urgent task.

The goal of the paper is increasing the efficiency of LPEC when operating in high-speed and force modes by reducing the amplitude of the recoil force by exciting its windings with a series of pulses from sections of the CES.

To excite LPEC from the CES, we use a half-wave polar pulse generated by the starting thyristor $V S$, assuming that its resistance in the forward direction is negligible and in the opposite direction its conductivity is equally small. Note that with such an excitation pulse, at the end of the operating cycle, a part of the energy is stored in the CES, which allows its further use [18, 19].

The mathematical model of LPEC. Consider the mathematical model of LPEC, which uses the lumped parameters of the active elements - IW and AW. This model allows to quickly calculate LPEC indicators when excited by a series of consecutive pulses. To take into account the interconnected electrical, magnetic, mechanical and thermal processes, as well as a number of non-linear dependencies, we present the solutions of the equations describing these processes in a recursive form. 
In the calculation, the workflow is divided into a number of numerically small time intervals $\Delta t=t_{k+1}-t_{k}$ within which we consider all quantities to be unchanged. With this approach, linear equations and relations can be used to determine the excitation current and voltage of the CES on the calculated time interval $\Delta t$.

Electrical processes in LPEC when excited by a single current pulse from the CES can be described by the equation [7]:

$$
\left[R_{1}\left(T_{1}\right)+R_{2}\left(T_{2}\right)\right] \cdot i+\frac{d \psi}{d t}+\frac{1}{C_{0}} \int_{0}^{t} i d t=0, \quad u_{C}(0)=U_{0},
$$

where $n=1,2$ are the indices of IW and AW, respectively; $R_{n}, T_{n}$ are the resistance and temperature of the $n$-th winding, respectively; $i$ is the current IW and AW; $C_{0}$ is the capacity of the CES charged to voltage $U_{0}$; $u_{C}$ is the voltage of the CES;

$$
\frac{d \psi}{d t}=\left[L_{1}-2 M_{12}(z)+L_{2}\right] \frac{d i}{d t}-2 i v_{z}(t) \frac{d M_{12}}{d z} ;
$$

where $L_{n}$ is the inductance of the $n$-th winding; $M_{12}(z)$ is the mutual inductance between the IW and the AW moving along the $z$ axis at speed $v_{z}$.

On a numerically small time interval $\Delta t$ we assume that all functional dependencies are unchanged: $R_{1}\left(T_{1}\right)=R_{1}, R_{2}\left(T_{2}\right)=R_{2}, M_{12}(z)=M_{12}, v_{z}(t)=v_{z}$.

Substituting equation (2) in (1) we obtain:

$$
\begin{aligned}
& \left(R_{1}+R_{2}-2 v_{z} \frac{d M_{12}}{d z}\right) \cdot i+\left[L_{1}-2 M_{12}+L_{2}\right] \frac{d i}{d t}+ \\
& +\frac{1}{C_{0}} \int_{0}^{t} i d t=0 .
\end{aligned}
$$
form:

The solution to equation (3) will be sought in the

$$
i=A_{1} \exp \left(\alpha_{1} t\right)+A_{2} \exp \left(\alpha_{2} t\right)
$$

where $\alpha_{1,2}=-0,5 \frac{\Theta}{\Xi} \pm\left[0,25\left(\frac{\Theta}{\Xi}\right)^{2}-\frac{1}{C_{0} \Xi}\right]^{0,5}$ are the roots of the characteristic equation; $A_{1}, A_{2}$ are the arbitrary constants;

$$
\begin{gathered}
\Xi=L_{1}-2 M_{12}+L_{2} \\
\Theta=R_{1}+R_{2}-2 v_{z} \frac{d M_{12}}{d z} .
\end{gathered}
$$

If $\Theta>2 \sqrt{\Xi C_{0}^{-1}}$, then after a series of transformations we obtain expressions for arbitrary constants at time $t_{k}$ :

$$
A_{1,2}=\frac{u_{C}\left(t_{k}\right)+\Theta \cdot i\left(t_{k}\right)+\alpha_{2,1} \Xi \cdot i\left(t_{k}\right)}{\Xi \exp \left(\alpha_{1,2} t_{k}\right)\left(\alpha_{2,1}-\alpha_{1,2}\right)} .
$$

Substituting expressions (5) into equation (4), we obtain the expression for the current in a recurrent form:

$$
\begin{aligned}
& i\left(t_{k+1}\right)=\frac{u_{C}\left(t_{k}\right)+\Theta \cdot i\left(t_{k}\right)}{\Xi\left(\alpha_{2}-\alpha_{1}\right)}\left[\exp \left(\alpha_{1} \Delta t\right)-\exp \left(\alpha_{2} \Delta t\right)\right]+ \\
& +\frac{i\left(t_{k}\right)}{\alpha_{2}-\alpha_{1}}\left[\alpha_{2} \exp \left(\alpha_{1} \Delta t\right)-\alpha_{1} \exp \left(\alpha_{2} \Delta t\right)\right] .
\end{aligned}
$$

The voltage on the CES:

$$
\begin{aligned}
& u_{C}\left(t_{k+1}\right)=\frac{u_{C}\left(t_{k}\right)+\Theta \cdot i\left(t_{k}\right)}{\alpha_{2}-\alpha_{1}}\left[\alpha_{2} \exp \left(\alpha_{1} \Delta t\right)-\alpha_{1} \exp \left(\alpha_{2} \Delta t\right)\right]+ \\
& +\Xi \frac{i\left(t_{k}\right)}{\alpha_{2}-\alpha_{1}}\left[\alpha_{2}^{2} \exp \left(\alpha_{1} \Delta t\right)-\alpha_{1}^{2} \exp \left(\alpha_{2} \Delta t\right)\right]
\end{aligned}
$$

If $\Theta<2 \sqrt{\Xi C_{0}^{-1}}$, then the roots of the characteristic equation can be represented as:

$$
\alpha_{1,2}=-\delta \pm j \omega_{1}=\omega_{0} \exp (j(\pi \pm \theta)),
$$

where $\quad \delta=0,5 \Theta \Xi^{-1} ; \quad \theta=\operatorname{arctg}\left(4 \Xi \Theta^{-2} C_{0}^{-1}-1\right)^{0,5}$; $\omega_{0}=\left(\Xi C_{0}\right)^{-0,5} ; \omega_{1}=\left(\Xi^{-1} C_{0}^{-1}-0.25 \Theta^{2} \Xi^{-2}\right)^{0,5}$.

Substituting the values of the roots (8) in equation (6) and taking into account that

$$
2 j \sin \left(\omega_{1} \Delta t\right)=\exp \left(j \omega_{1} \Delta t\right)-\exp \left(-j \omega_{1} \Delta t\right),
$$

we obtain:

$$
\begin{aligned}
& i\left(t_{k+1}\right)=-\omega_{1}^{-1} \exp (-\delta \Delta t)\left\{\Xi^{-1}\left[u_{C}\left(t_{k}\right)+\Theta \cdot i\left(t_{k}\right)\right] \times\right. \\
& \left.\times \sin \left(\omega_{1} \Delta t\right)+\omega_{0} i\left(t_{k}\right) \sin \left(\omega_{1} \Delta t-\theta\right)\right\} .
\end{aligned}
$$

The voltage on the CES in this case:

$$
u_{C}\left(t_{k+1}\right)=-\omega_{0} \omega_{1}^{-1} \exp (-\delta \Delta t)\left\{\left[u_{C}\left(t_{k}\right)+\Theta \cdot i\left(t_{k}\right)\right] \times\right.
$$$$
\left.\times \sin \left(\omega_{1} \Delta t-\theta\right)+i\left(t_{k}\right) \omega_{0} \Xi \sin \left(\omega_{1} \Delta t-2 \theta\right)\right\} \text {. }
$$

If $\Theta=2 \sqrt{\Xi C_{0}^{-1}}$, then $\delta=\omega_{0}$ and the current is:

$$
\begin{aligned}
& i\left(t_{k+1}\right)=\exp (-\delta \Delta t) \Delta t\left\{i\left(t_{k}\right) \delta-\Xi^{-1} \times\right. \\
& \left.\times\left[u_{C}\left(t_{k}\right)+\Theta \cdot i\left(t_{k}\right)\right]\right\} .
\end{aligned}
$$

The voltage on the CES in this case:

$$
\begin{aligned}
& u_{C}\left(t_{k+1}\right)=\left[u_{C}\left(t_{k}\right)-i\left(t_{k}\right) \Xi \delta+\Theta \cdot i\left(t_{k}\right)\right](\delta \Delta t+1) \times \\
& \times \exp (-\delta \Delta t)+i\left(t_{k}\right)(\Xi \delta-\Theta) .
\end{aligned}
$$

The value of the displacement of AW with A relative to IW can be represented as a recurrence relation:

$$
h_{z}\left(t_{k+1}\right)=h_{z}\left(t_{k}\right)+v_{z}\left(t_{k}\right) \Delta t+\vartheta \cdot \Delta t^{2} /\left(m_{a}+m_{2}\right)
$$
where $v_{z}\left(t_{k+1}\right)=v_{z}\left(t_{k}\right)+\vartheta \cdot \Delta t /\left(m_{a}+m_{2}\right)$ is the speed of AW with A;

$\vartheta=f_{z}(z, t)-K_{T} v_{z}\left(t_{k}\right)-0,125 \pi \gamma_{a} \beta_{a} D_{e 2}^{2} v_{z}^{2}\left(t_{k}\right)$;

$f_{z}(z, t)=i^{2}\left(t_{k}\right) \frac{d M_{12}}{d z}(z)$ is the instantaneous value of axial EDF between windings; $m_{2}, m_{a}$ are the masses of $\mathrm{AW}$ and A, respectively; $h_{z}$ is the value of displacement of AW with $\mathrm{A} ; K_{T}$ is the dynamic friction coefficient; $\gamma_{a}$ is the density of the medium fir movement; $\beta_{a}$ is the drag coefficient; $D_{e 2}$ is the outer diameter of A.

When LPEC is operating in force mode, there is thermal contact between the IW and the AW through an insulating gasket. The temperature of the $n$-th LPEC winding can be described by the recurrence relation [20]:

$$
\begin{aligned}
& \quad T_{n}\left(t_{k+1}\right)=T_{n}\left(t_{k}\right) \xi+(1-\xi)\left[\pi^{-1} i^{2}\left(t_{k}\right) R_{n}\left(T_{n}\right)\left(D_{e n}^{2}-D_{i n}^{2}\right)^{-1}+\right. \\
& \left.\quad+0,25 \pi T_{0} D_{e n} H_{n} \alpha_{T n}+T_{m}\left(t_{k}\right) \lambda_{a}(T) d_{a}^{-1}\right] \times \\
& \quad \times\left\{0,25 \pi \alpha_{T n} D_{e n} H_{n}+\lambda_{a}(T) d_{a}^{-1}\right\}^{-1}, \\
& \text { where } \xi=\exp \left\{-\frac{\Delta t}{c_{n}\left(T_{n}\right) \gamma_{n}}\left(0,25 D_{e n} \alpha_{T n}+\frac{\lambda_{a}(T)}{d_{a} H_{n}}\right)\right\} ;
\end{aligned}
$$


$\lambda_{a}(T)$ is the thermal conductivity coefficient of the gasket; $d_{a}$ is the thickness of the gasket; $D_{e n}, D_{i n}$ are the outer and inner diameters of the $n$-th winding, respectively; $\alpha_{T n}, c_{n}$ are the heat transfer coefficient and heat capacity of the $n$ th winding, respectively.

When LPEC is operating in high-speed mode, the temperature of the $n$-th winding can be described by the recurrence relation [20]:

$$
\begin{aligned}
& T_{n}\left(t_{k+1}\right)=T_{n}\left(t_{k}\right) \chi+(1-\chi)\left[T_{0}+4 \pi^{-2} i^{2}\left(t_{k}\right) \times\right. \\
& \left.\times R_{n}\left(T_{n}\right) \alpha_{T n}^{-1} D_{e n}^{-1} H_{n}^{-1}\left(D_{e n}^{2}-D_{\text {in }}^{2}\right)^{-1}\right],
\end{aligned}
$$

where $\chi=\exp \left\{-0,25 \Delta t D_{e n} \alpha_{T n} c_{n}^{-1}\left(T_{n}\right) \gamma_{n}^{-1}\right\}$.

To calculate the characteristics and indicators of LPEC, we use a cyclic action algorithm that allows to take into account a set of interrelated processes and various nonlinear dependencies, for example, $R_{n}\left(T_{n}\right)$, $M_{12}(z)$. Based on the current values obtained at time $t_{k+1}$, the temperatures of the windings $T_{1}$ and $T_{2}$, the displacement $h_{z}$ and the speed of the AW $v_{z}$, the mutual inductance $M_{12}$ between the windings, etc. are calculated. The value of the calculation step $\Delta t$ is chosen so that it does not significantly affect the calculation results, providing with the necessary accuracy.

The initial conditions of the mathematical model: $T_{n}(0)=T_{0}$ is the temperature of the $n$-th winding; $i_{n}(0)=0$ is the current of the ток $n$-th winding; $h_{z}(0)=h_{z 0}$ is the distance between IW and AW; $u_{c}(0)=U_{0}$ is the CES voltage;

$v_{z}(0)=0$ is the AW speed along the $z$ axis.

The main parameters of LIPET. Let us consider LPEC, in which IW $(n=1)$ and AW $(n=2)$ are made in the form of two-layer disk coils. IW is wound with a copper bus bar with cross section of $1.2 \times 5.0 \mathrm{~mm}^{2}$, and AW is wound with a copper bus bar with cross section of $1.2 \times 2.5 \mathrm{~mm}^{2}$. Number of turns of the $n$-th winding $N_{n}=60$, outer diameter $D_{e n}=100 \mathrm{~mm}$, inner diameter $D_{\text {in }}=8 \mathrm{~mm}$. CES: energy $W_{0}=180 \mathrm{~J}$, voltage $U_{0}=300 \mathrm{~V}$. The initial distance between the windings is $h_{z 0}=1 \mathrm{~mm}$.

When LPEC is operating in high-speed mode, we use A with mass of $m_{a}=0.5 \mathrm{~kg}$, and evaluate its effectiveness with maximum speed $v_{z m}$ at minimum recoil force. When LPEC is operating in the force mode, we assume that there is no displacement of the AW with the A $\left(m_{a}=\propto\right)$, and its efficiency will be estimated using the maximum value of the EDF impulse $P_{z}=\int f_{z}(z, t) d t$ at the minimum recoil force.

LPEC excitation by a single pulse is carried out from the CES with capacitance $C_{0}=4 \mathrm{mF}$. When operating in the power mode (Fig. 2), the current amplitude in the LPEC windings is $i_{m}=1.478 \mathrm{kA}$, which leads to the appearance of EDF with amplitude of $f_{z m}=10.56 \mathrm{kN}$ between the windings. The value of the EDF impulse at the end of the operating process $(1.65 \mathrm{~ms})$ is $P_{z}=7.88 \mathrm{~N} \cdot \mathrm{s}$. Note that the temperature rises of the windings $\theta_{n}=T_{0}-T_{n}$ are negligible $\left(\theta_{1}=0.2{ }^{\circ} \mathrm{C}\right.$, $\theta_{2}=0.7^{\circ} \mathrm{C}$ ).

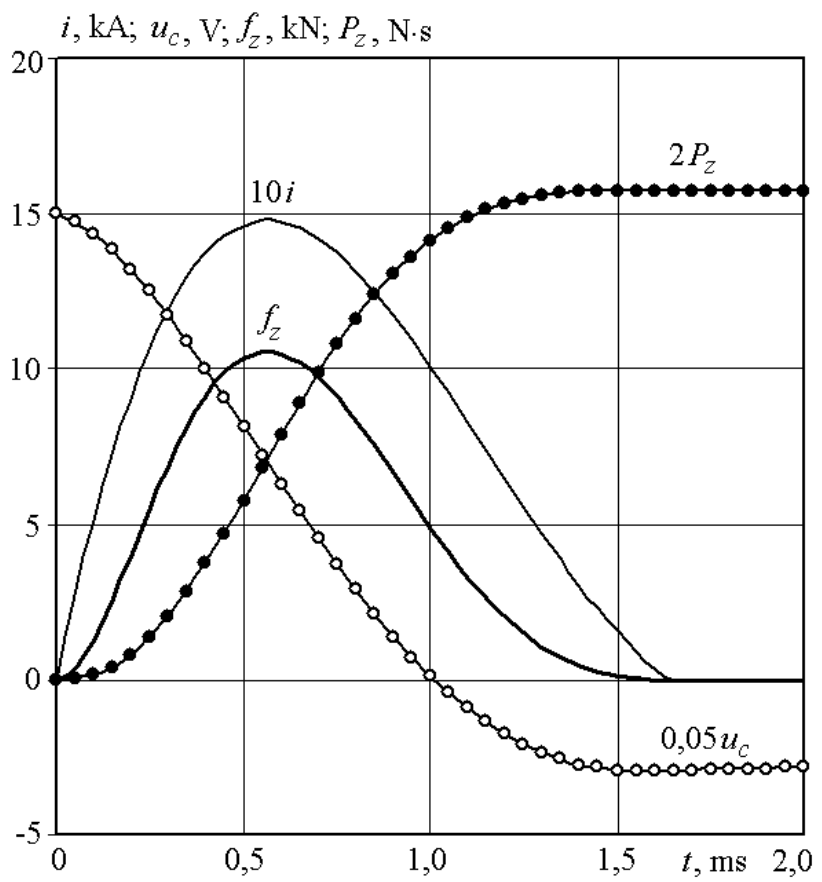

Fig. 2. Electrodynamic characteristics of LPEC when operating in force mode

When operating in high-speed mode, the operating process is delayed up to $2 \mathrm{~ms}$ with a decrease in all the main indicators (Fig. 3). The amplitude of the current in the windings decreases to $i_{m}=1.375 \mathrm{kA}$, which leads to a decrease in the amplitude of the EDF between the windings to a value of $f_{z m}=8.67 \mathrm{kN}$. The value of the EDF impulse at the end of the operating process is $P_{z}=6.2 \mathrm{~N} \cdot \mathrm{s}$. The temperature rises of the windings also decrease $\left(\theta_{1}=0.18{ }^{\circ} \mathrm{C}, \theta_{2}=0.6^{\circ} \mathrm{C}\right)$. Such a change in the operating process is due to the movement of $\mathrm{AW}$ with $\mathrm{A}$, which reach maximum speed of $v_{z m}=7.1 \mathrm{~m} / \mathrm{s}$.

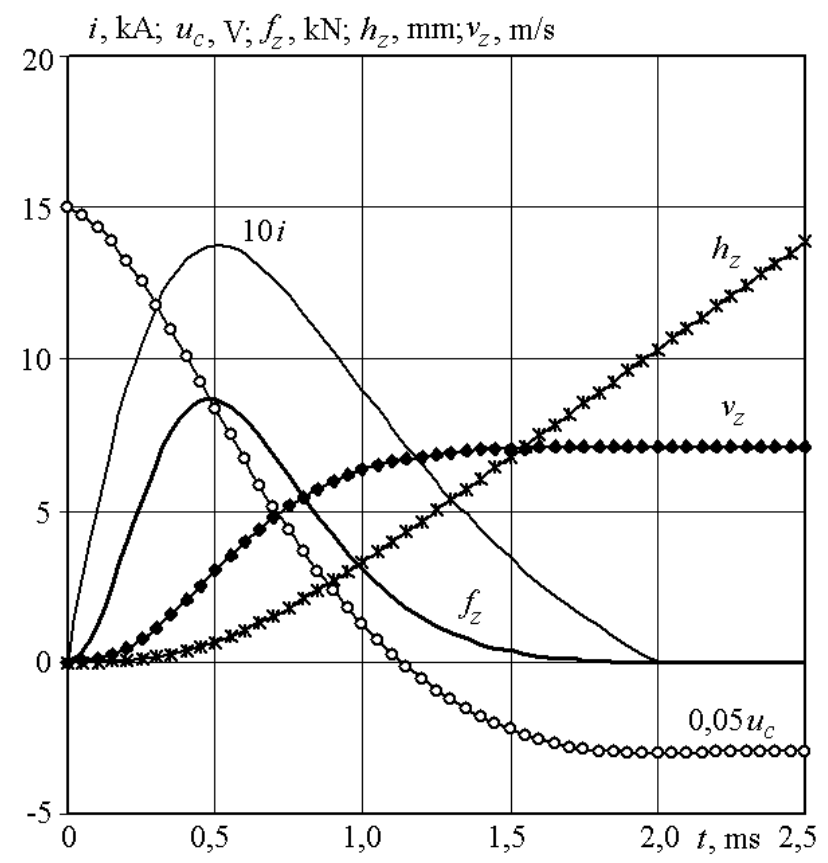

Fig. 3. Electrodynamic characteristics of LPEC when operating in high-speed mode 
LPEC excitation by a series of pulses is carried out by sequentially connection in time to the terminals $a$ and $b$ of the sections of the CES. This forms a parallel connection of the sections of the CES to the converter windings.

Note that the parallel connection of the sections of the CES to the IW of a linear pulse induction accelerator was studied in [21, 22]. However, in these studies, all sections of the CES are connected to the IW simultaneously.

The total capacity of the sections is equal to $C_{0}=4 \mathrm{mF}$. The delay time for connecting the sections determines the repetition period of the excitation current pulses. With this method of excitation, the efficiency of LPEC in force and high-speed modes is evaluated by dimensionless criteria:

$$
K_{p}^{*}=\frac{P_{z}}{f_{z m}} \frac{f_{z m}^{0}}{P_{z}^{0}}, K_{v}^{*}=\frac{v_{z m}}{f_{z m}} \frac{f_{z m}^{0}}{v_{z m}^{0}},
$$

where $f_{z m}^{0}, P_{z}^{0}, v_{z m}^{0}$ are the values of the amplitude and impulse of the EDF, the speed of the AW with A, respectively, when excited by a single pulse.

The essence of these criteria is to ensure the greatest value of the EDF impulse for the force mode, and the highest speed of the AW with A for the high-speed mode with minimum amplitude of the EDF which determines the recoil force. These criteria evaluate the efficiency of LPEC when excited by a series of pulses with respect to excitation by a single pulse.

Figure 4 shows the electrodynamic characteristics of LPEC when operating in force mode from five identical sections of the CES connected to the windings in series with a delay of $0.75 \mathrm{~ms}$. For each excitation pulse, the current amplitude is practically unchanged and is $i_{m}=0.788 \mathrm{kA}$, which is almost 2 times less than when excited by a single pulse. The amplitude of the EDF decreases even more, reaching $f_{z m}=3 \mathrm{kN}$. The value of the EDF impulse at the end of the operating process also decreases, but to a lesser extent, amounting to $P_{z}=4.9 \mathrm{~N} \cdot \mathrm{s}$. The temperature rises of the windings also decrease $\left(\theta_{1}=0.13{ }^{\circ} \mathrm{C}, \theta_{2}=0.42{ }^{\circ} \mathrm{C}\right)$. However, the efficiency criterion of the converter $K_{p}^{*}$ increases by more than 2 times, compared with its excitation by a single pulse.

Figure 5 shows the electromechanical characteristics of LPEC when operating in high-speed mode from five identical sections of the CES connected to the windings in series with a delay of $1 \mathrm{~ms}$. A feature of this converter is a sequential decrease in the amplitudes of the currents $i_{m}$ and EDF $f_{z m}$ when connecting sections of the CES. Such a decrease in these amplitudes is due to the sequential weakening of the magnetic coupling between the windings due to the displacement of the AW by an value of $h_{z}$. In this converter, the largest amplitudes are observed in the first pulse, amounting to current $i_{m}=0.783 \mathrm{kA}$, for $\operatorname{EDF} f_{z m}=2.95 \mathrm{kN}$. The value of the EDF impulse in this case is $P_{z}=3.34 \mathrm{~N} \cdot \mathrm{s}$, providing the speed of the AW with A $v_{z}=3.82 \mathrm{~m} / \mathrm{s}$. The temperature rises of the windings are $\theta_{1}=0.11^{\circ} \mathrm{C}, \theta_{2}=0.37{ }^{\circ} \mathrm{C}$. Thus, in the high-speed mode, all indicators of LPEC, excited by a series of five pulses, decrease in comparison with excitation by a single pulse, but the criterion of converter efficiency $K_{v}^{*}$ increases in this case by $58 \%$.

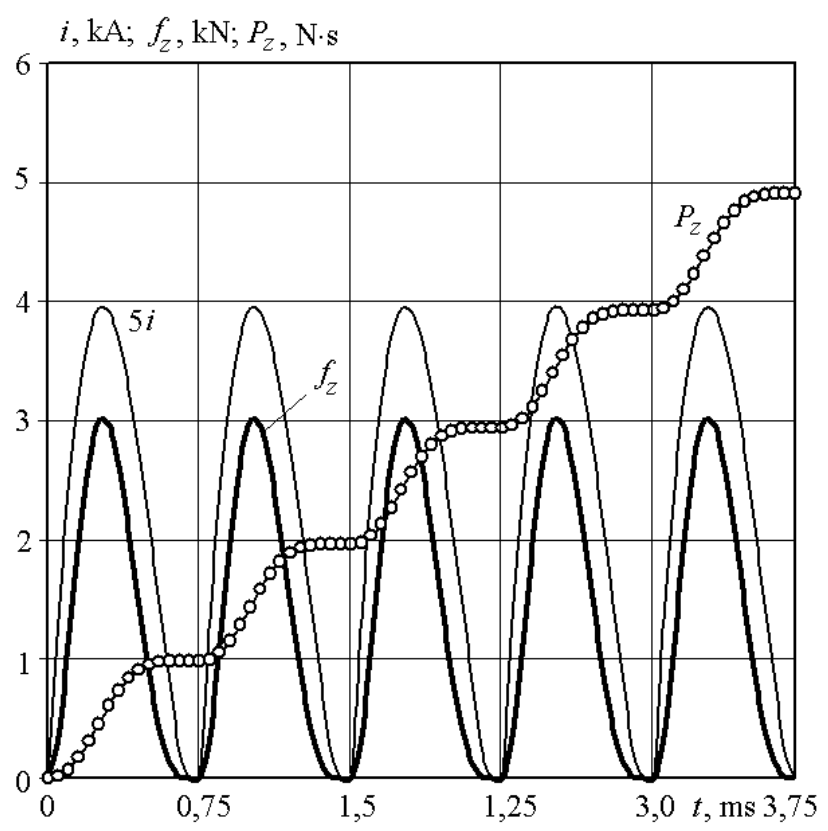

Fig. 4. Electrodynamic characteristics of LPEC when excited from the same sections of the CES

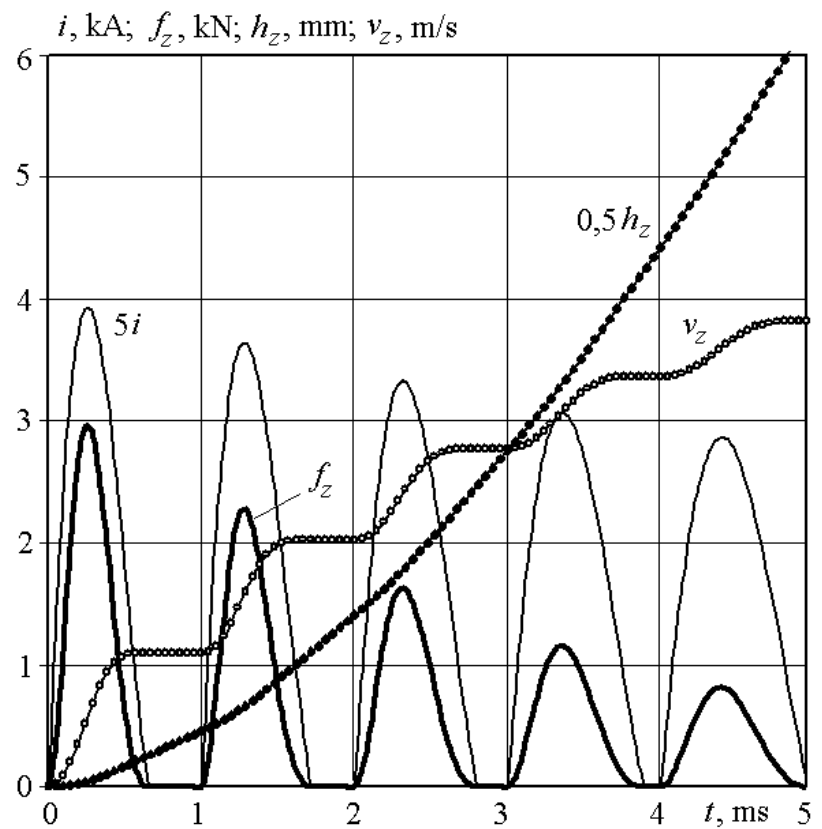

Fig. 5. Electromechanical characteristics of LPEC when excited from the same sections of the CES

To assess the effect of the number of excitation pulses $N_{i}$ on the LPEC parameters, Fig. 6 is used. Both in force and in high-speed operation modes, with an increase in the number of excitation pulses $N_{i}$, a constant voltage of the sections of the CES $U_{0}=300 \mathrm{~V}$ and conservation of their total energy $W_{0}=180 \mathrm{~J}$, all the main indicators decrease. These are the amplitudes of the currents $i_{m}$ and 
the EDF $f_{z m}$, the value of the impulse of the EMF $P_{z}$ and the speed of the AW with A $v_{z}$. But due to a stronger decrease in the amplitude of the $\operatorname{EDF} f_{z m}$, which manifests itself as the recoil force, from an increase in the number of excitation pulses, the efficiency criteria of LPEC $K_{p}^{*}$ and $K_{v}^{*}$ also increase.
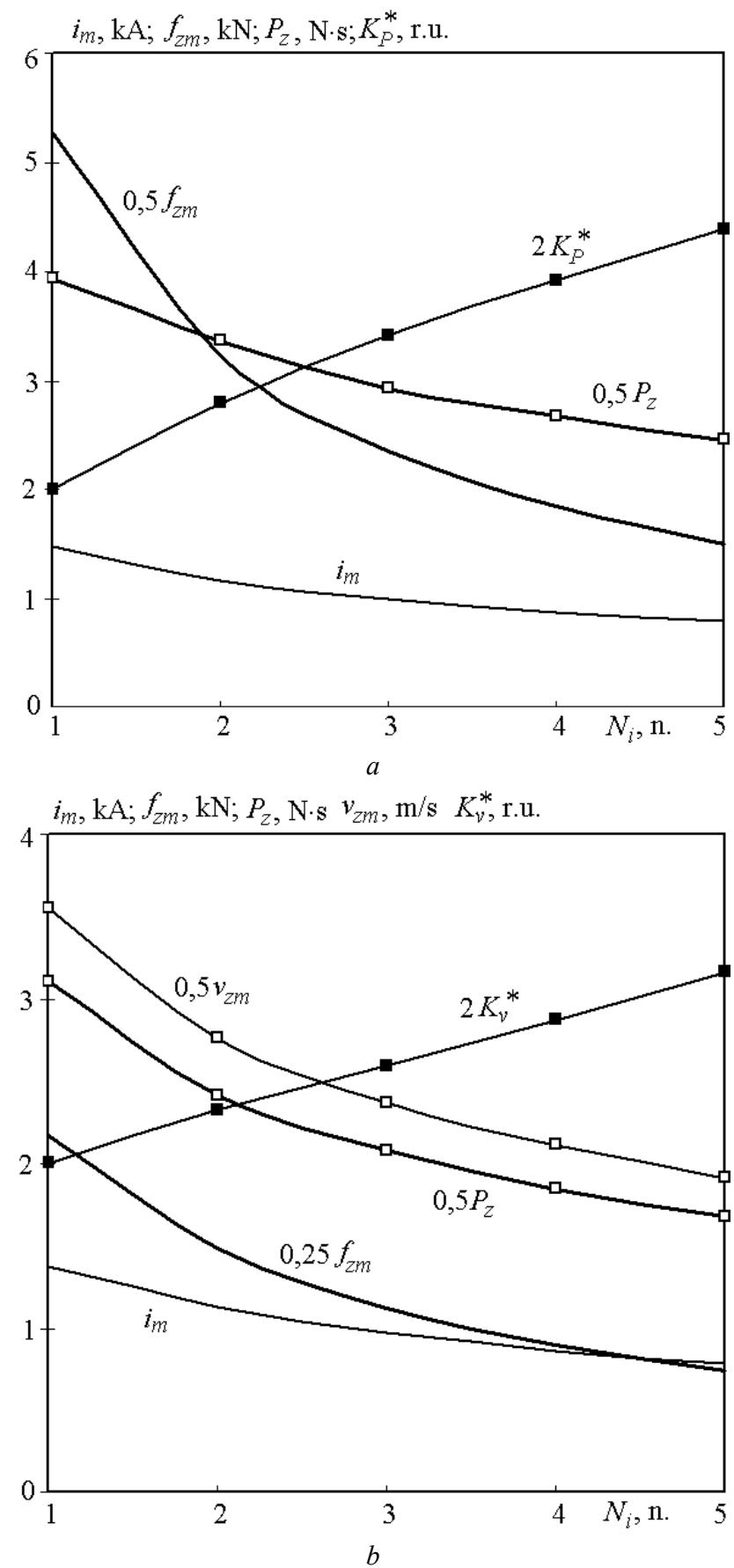

Fig. 6. Dependence of the performance of LPEC in force $(a)$ and high-speed $(b)$ modes on the number of excitation pulses

The maximum amplitudes of the current and EDF in the first pulse of the series for LPEC operating in highspeed mode can be reduced by sequentially increasing the capacitance of the sections of the CES while maintaining their total value $C_{0}=4 \mathrm{mF}$.
Figure 7 shows the electromechanical characteristics of LPEC when operating in high-speed mode and excitation from five sections of the CES, whose capacitances linearly increase from $0.4 \mathrm{mF}$ in the first section to $1.2 \mathrm{mF}$ in the fifth section.

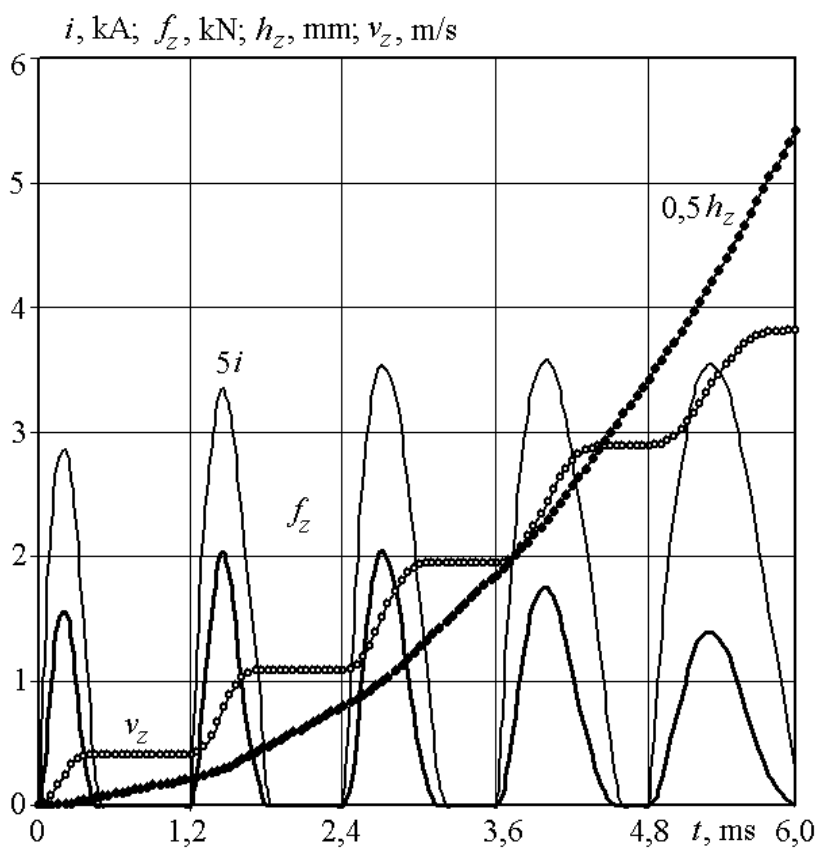

Fig. 7. Electromechanical characteristics of LPEC when operating in high-speed mode and excitation from sections of the CES, the capacities of which increase linearly

With this excitation, of LPEC operating in highspeed mode, the maximum current amplitude is observed not in the first but in the fourth pulse of the series and is $i_{m}=713.9 \mathrm{~A}$, which is lower than when excited from identical sections of the CES. The maximum amplitude of the EDF is observed in the third pulse of the series and amounts to $f_{z m}=2.04 \mathrm{kN}$. Note that the decrease in the current amplitude after the fourth pulse of the series is due to the weakening of the magnetic coupling between the IW and AW. A decrease in the amplitudes of the EDF after the third pulse of the series is additionally caused by an increase in the distance between them.

With this method of LPEC excitation, the value of the EDF impulse is $P_{z}=3.33 \mathrm{~N} \cdot \mathrm{s}$, which ensures the speed of the AW with A $v_{z}=3.81 \mathrm{~m} / \mathrm{s}$.

Figure 8 shows the electrodynamic characteristics of LPEC during operation in the force mode and excitation from five sections of the CES, whose capacitances linearly increase from $0.5 \mathrm{mF}$ in the first section to $1.1 \mathrm{mF}$ in the fifth section. With this excitation of LPEC operating in the force mode, the maximum current amplitude arises in the fifth pulse of the series and is equal to $i_{m}=908 \mathrm{~A}$, which is higher than when excited from identical sections of the CES. The maximum amplitude of the EDF also occurs in the fifth pulse of the series and amounts to $f_{z m}=3.98 \mathrm{kN}$. The value of the impulse of EDF is $P_{z}=4.98 \mathrm{~N} \cdot \mathrm{s}$. 


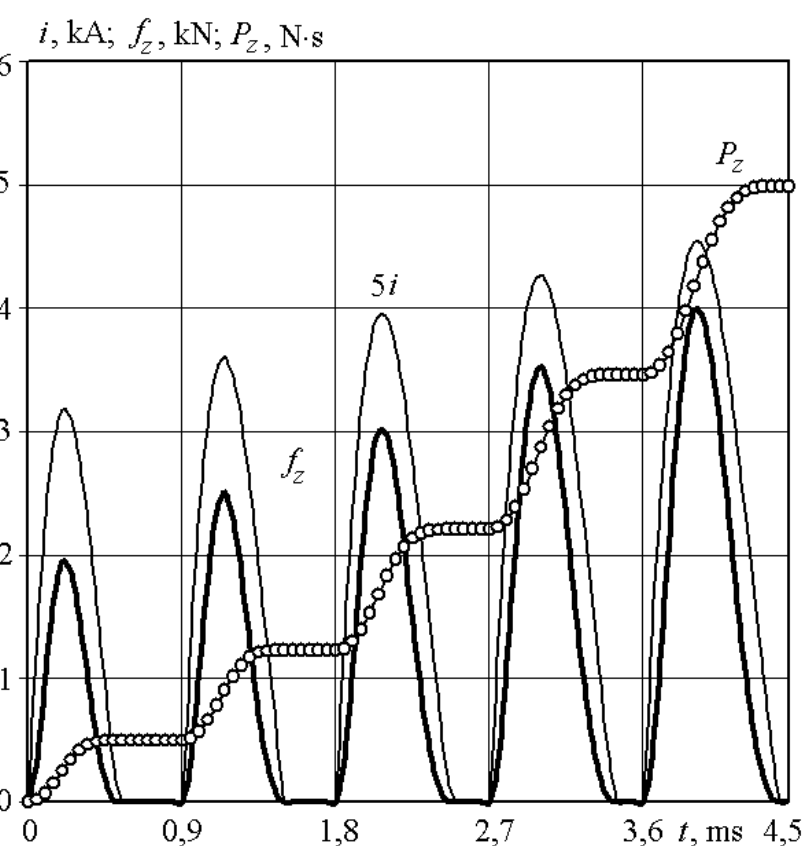

Fig. 8. Electrodynamic characteristics of LIPET when operating in force mode and excitation from sections of the CES, the capacities of which increase linearly

To assess the effect of the regularity of the distribution of capacitances in sections of the CES on the performance of LPEC when operating in high-speed and force modes, Fig. 9 is used, where the indicator of the distribution of capacitances in sections of the CES is used:

$$
K_{c}^{*}=2\left(C_{\max }-C_{\min }\right)\left(C_{\max }+C_{\min }\right)^{-1},
$$

where $C_{\min }, C_{\max }$ are the capacitances of the first and fifth sections of the CES, respectively.

Note that at $K_{c}^{*}=0$ the capacitances of all five sections of the CES are the same.

When LPEC is operating in high-speed mode, an increase in the indicator $K_{c}^{*}$ substantially changes only the maximum amplitude of the EDF $\boldsymbol{f}_{\boldsymbol{z}}$ which noticeably decreases in the interval $K_{c}^{*} \subset(0,1)$. This affects the efficiency criterion $K_{v}^{*}$, the maximum value of which will be at $K_{c}^{*}=1\left(C_{\min }=0.4 \mathrm{mF}, C_{\max }=1.2 \mathrm{mF}\right)$. If the indicator $K_{c}^{*}$ exceeds 1 , the efficiency criterion $K_{v}^{*}$ decreases due to an increase in the amplitude of the EDF in the last fifth pulse of the series. When LPEC is operating in force mode, an increase in the indicator $K_{c}^{*}$ leads to an increase in the maximum amplitude of the $\operatorname{EDF} f_{z m}$, as a result of which the efficiency criterion $K_{p}^{*}$ decreases.

Thus, when excitation by a series of pulses from sections of the CES by reducing the amplitude of the recoil force, an increase in the efficiency of LPEC is provided. For a converter operating in high-speed mode, it is advisable to increase the indicator of the distribution of capacitances in sections of the CES to a certain value $\left(K_{c}^{*}=1\right)$. For a converter operating in force mode, it is advisable to use the same capacitances for all sections of the CES.
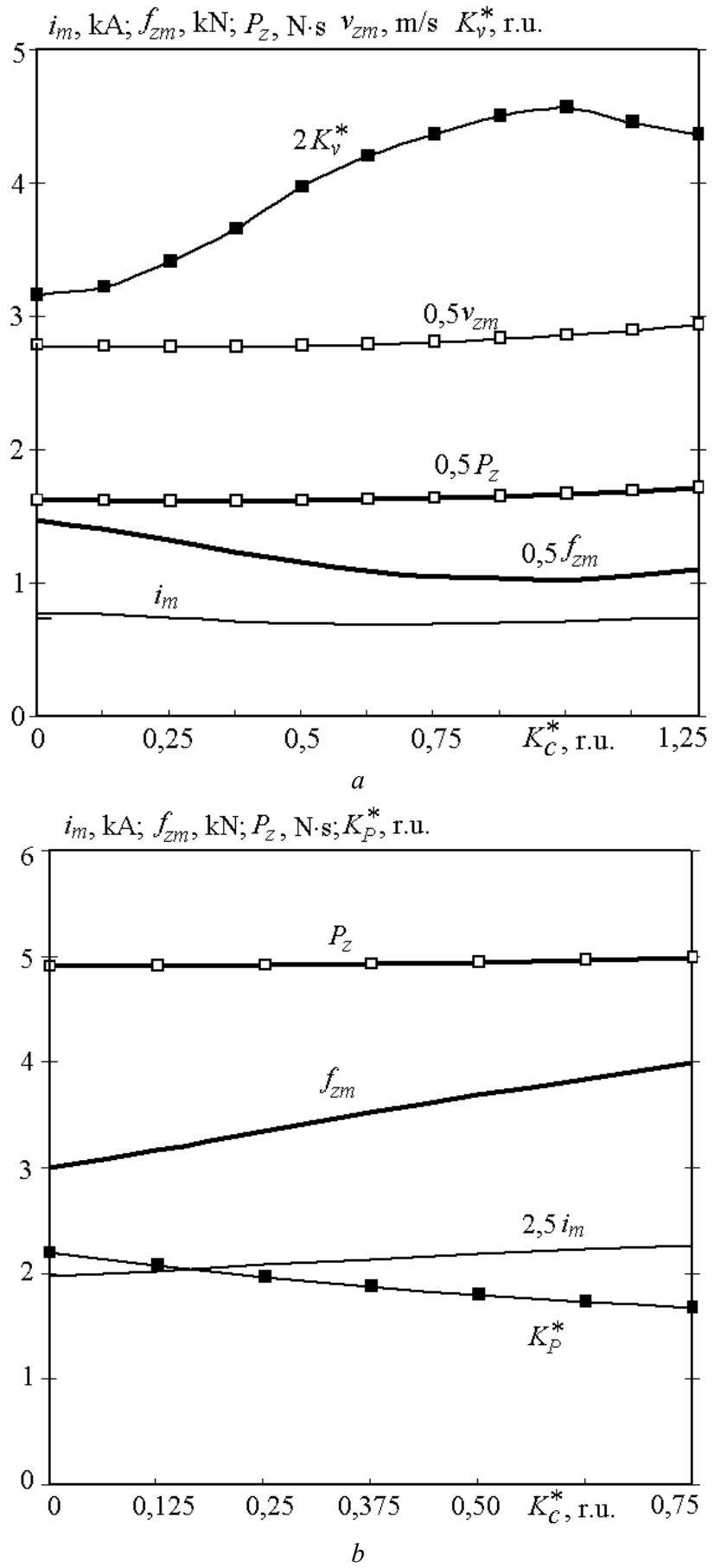

Fig. 9. Dependence of the performance of LPEC in high-speed $(a)$ and force $(b)$ modes on the indicator of the distribution of capacitances in sections of the CES

\section{Conclusions.}

1. It is shown that when the windings are excited by a series of pulses from sections of a capacitive energy storage unit (CES), an increase in the efficiency of a linear pulse electrodynamic type converter (LPEC) is 
ensured during operation in high-speed and force modes due to a decrease in the amplitude of the recoil force.

2. A mathematical model of LPEC is presented, in which the solutions of the equations describing the interconnected electrical, magnetic, mechanical and thermal processes are presented in a recursive form.

3 . It has been established that at excitation by singlepulse of LPEC operating in a high-speed mode, compared with a force mode, the current amplitude in the windings decreases by $7.5 \%$, the amplitudes of electrodynamic forces (EDFs) - by $21.8 \%$, the value of the EDF impulse - by $27.1 \%$. In this case, the armature winding with the actuating element accelerates to speed of $7.1 \mathrm{~m} / \mathrm{s}$.

4. It has been established that at excitation by a series of pulses from the same sections of the CES during LPEC operation in the force mode, the amplitudes of the current pulses and the EDF are practically unchanged, while when operating in high-speed mode, the amplitudes of the currents and EDF decrease sequentially. An increase in the number of excitation pulses while conserving the energy of the CES leads to a decrease in the main indicators of LPEC. But due to a decrease in the amplitude of the EDF, which manifests itself as a recoil force, the efficiency of LPEC is increased.

5. For LPEC operating in high-speed mode, a consistent increase in the capacitances of sections of the CES, forming a series of excitation pulses, is justified. For LPEC, operating in force mode, it is advisable to use the same capacitances of all sections of the CES.

\section{REFERENCES}

1. Bissal A., Magnusson J., Engdahl G. Comparison of two ultra-fast actuator concept. IEEE Transactions on Magnetics, 2012, vol. 48, no. 11, pp. 3315-3318. doi: 10.1109/tmag.2012.2198447.

2. Tomashevsky D.N., Koshkin A.N. Modeling of linear impulse electric motors. Russian Electrical Engineering, 2006, no. 1, pp. 24-27. (Rus).

3. J. Young-woo, L. Hyun-wook, L. Seok-won. High-speed AC circuit breaker and high-speed OCD. Proceeding of the conf. «22-th international conference on electricity distribution». 2013, 10-13 June, Stockholm. - Paper 608.

4. D.-K. Lim, D.-K. Woo, I.-W. Kim, D.-K. Shin, J.-S. Ro, T.K. Chung, H.-K. Jung. Characteristic Analysis and Design of a Thomson Coil Actuator Using an Analytic Method and a Numerical Method. IEEE Transactions on Magnetics, 2013, vol. 49, no. 12, pp. 5749-5755. doi: 10.1109/tmag.2013.2272561.

5. Puumala V., Kettunen L. Electromagnetic design of ultrafast electromechanical switches. IEEE Transactions on Power Delivery, 2015, vol. 30, no. 3, pp. 1104-1109. doi: 10.1109/TPWRD.2014.2362996.

6. Bolyukh V.F., Kashanskij Yu.V., Schukin I.S. Influence of geometrical parameters of the inductor and armature on the indicators of a linear pulse electromechanical converter of an electrodynamic type. Electrical engineering \& electromechanics, 2019, no. 3, pp. 11-17. doi: 10.20998/2074272X.2019.3.02.

7. Bolyukh V.F., Kashanskyi Yu.V., Shchukin I.S. Comparative analysis of power and speed indicators linear pulse electromechanical converters electrodynamic and induction types. Technical electrodynamics, 2019, no. 6, pp. 35-42. (Rus). doi: 10.15407/techned2019.06.035.

8. Bolyukh V.F., Oleksenko S.V., Shchukin I.S. Comparative analysis of linear pulse electromechanical converters electromagnetic and induction types. Technical electrodynamics, 2016, no. 5, pp. 46-48. (Rus). doi: 10.15407/techned2016.05.046.

9. Mishkin V.N., Tolstik A.I. Comparative evaluation of arresting devices on the electrodynamic and electromagnetic principle of action. Electromagnetic pulse systems, 1989, pp. 114-117. (Rus).

10. Balikci A., Zabar Z., Birenbaum L., Czarkowski D. Improved performance of linear induction launchers. IEEE Transactions on Magnetics, 2005, vol. 41, no. 1, pp. 171-175. doi: 10.1109/tmag.2004.839283.

11. Abdalla M.A., Mohamed H.M. Asymmetric multistage synchronous inductive coilgun for length reduction, higher muzzle velocity and launching time reduction. IEEE Transactions on Plasma Science, 2016, vol. 44, no. 5, pp. 785789. doi: 10.1109/TPS.2016.2543500.

12. Bolyukh V.F., Vinnichenko A.I. Concept of an inductiondynamic catapult for a ballistic laser gravimeter. Measurement Techniques, 2014, vol. 56, iss. 10, pp. 1098-1104. doi: 10.1007/s11018-014-0337-z.

13. Bolyukh V.F., Omel'chenko A.V., Vinnichenko A.I. Effect of self-seismic oscillations of the foundation on the readout of a ballistic gravimeter with an induction-dynamic catapult. Measurement Techniques, 2015, vol. 58, no. 2, pp. 137-142. doi: 10.1007/s11018-015-0675-5.

14. Zhou Y., Huang Y., Wen W., Lu J., Cheng T., Gaoet S. Research on a novel drive unit of fast mechanical switch with modular double capacitors. Journal of Engineering, 2019, vol. 2019, no. 17, pp. 4345-4348. doi: 10.1049/joe.2018.8148.

15. Fan G., Wang Y., Hu Y., Yan Z. Research on energy recovery system based on HTSM for synchronous induction electromagnetic launcher system. IEEE Transaction on Plasma Science, 2020, vol. 48, no. 1, pp. 291-298. doi: 10.1109/TPS.2019.2960038.

16. Guangcheng F., Wang Y., Xu Q., Xinyi N., Yan Z. Design and analysis of a novel three-coil reconnection electromagnetic launcher. IEEE Transactions on Plasma Science, 2019, vol. 47, no. 1, pp. 814-820. doi: 10.1109/TPS.2018.2874287.

17. Niu X., Li W., Feng J. Nonparametric modeling and parameter optimization of multistage synchronous induction coilgun. IEEE Transactions on Plasma Science, 2019, vol. 47, no. 7, pp. 3246-3255. doi: 10.1109/TPS.2019.2918157.

18. Bolyukh V.F., Katkov I.I. Influence of the Form of Pulse of Excitation on the Speed and Power Parameters of the Linear Pulse Electromechanical Converter of the Induction Type. Volume 2B: Advanced Manufacturing, Nov. 2019, 8 p. doi: 10.1115/IMECE2019-10388.

19. Liu X., Yu X., Ban R., Li Z. Analysis of the capacitor-aided meat grinder circuits for an inductive pulsed power supply. IEEE Transactions on Plasma Science, 2017, vol. 45, no. 7, pp. 1339-1346. doi: 10.1109/TPS.2017.2705179.

20. Bolyukh V.F., Shchukin I.S. The thermal state of an electromechanical induction converter with impact action in the cyclic operation mode. Russian electrical engineering, 2012, vol.83, no.10, pp. 571-576. doi: 10.3103/s1068371212100045.

21. Vilchis-Rodriguez D.S., Shuttleworth R., Barnes M. Experimental Validation of a Finite Element 2D Axial Thomson Coil Model with Inductance and Resistance Compensation. 13th IET International Conference on $A C$ and $D C$ Power 
Transmission (ACDC 2017), 2017, Manchester, UK, 14-16 Feb. 2017. doi: 10.1049/cp.2017.0032.

22. Yadong Z., Ying W., Jiangjun R. Capacitor-driven coil-gun scaling relationships. IEEE Transactions on Plasma Science, 2011, vol. 39, no. 1, pp. 220-224. doi: 10.1109/TPS.2010.2052266.
V.F. Bolyukh ${ }^{1}$, Doctor of Technical Science, Professor, I.S. Schukin ${ }^{2}$, Candidate of Technical Science, Associate Professor,

${ }^{1}$ National Technical University «Kharkiv Polytechnic Institute», 2, Kyrpychova Str., Kharkiv, 61002, Ukraine, e-mail: vfbolyukh@gmail.com

${ }^{2}$ Firm Tetra, LTD,

Received 18.05.2020 18, Gudanova Str., Kharkiv, 61024, Ukraine, e-mail: tech@tetra.kharkiv.com.ua

How to cite this article:

Bolyukh V.F., Schukin I.S. Excitation with a series of pulses of a linear pulse electrodynamic type converter operating in power and high-speed modes. Electrical engineering \& electromechanics, 2020, no. 4, pp. 3-11. doi: 10.20998/2074272X.2020.4.01. 